\title{
A Naturopathic Approach to the Prevention of Cardiovascular Disease
}

\author{
Cost-Effectiveness Analysis of a Pragmatic Multi-Worksite Randomized \\ Clinical Trial
}

\author{
Patricia M. Herman, ND, PhD, Orest Szczurko, ND, MSc, Kieran Cooley, ND, MSc, and Dugald Seely, ND, MSc
}

\begin{abstract}
Objective: To determine the cost-effectiveness of a worksite-based naturopathic (individualized lifestyle counseling and nutritional medicine) approach to primary prevention of cardiovascular disease (CVD). Methods: Economic evaluation alongside a pragmatic, multi-worksite, randomized controlled trial comparing enhanced usual care (EUC; usual care plus biometric screening) to the addition of a naturopathic approach to CVD prevention (NC+EUC). Results: After 1 year, $\mathrm{NC}+\mathrm{EUC}$ resulted in a net decrease of 3.3 (confidence interval: 1.7 to 4.8 ) percentage points in 10-year CVD event risk (number needed to treat $=30$ ). These risk reductions came with average net study-year savings of $\$ 1138$ in societal costs and $\$ 1187$ in employer costs. There was no change in quality-adjusted life years across the study year. Conclusions: A naturopathic approach to CVD primary prevention significantly reduced CVD risk over usual care plus biometric screening and reduced costs to society and employers in this multi-worksite-based study. Trial Registration clinicaltrials.gov Identifier: NCT00718796.
\end{abstract}

$\mathrm{H}$ eart disease is the number one cause of death in the United States and the second most prevalent cause of death in Canada. ${ }^{1,2}$ Cardiovascular disease (CVD) - acute myocardial infarction, stroke, angina, transient ischemic attack, heart failure, and peripheral vascular disease - is also one of the most expensive diseases to treat and manage in terms of both direct medical costs and indirect costs (productivity losses). ${ }^{3,4}$ Yet, CVD is highly preventable. According to one estimate, $78 \%$ of the US population meet the criteria to benefit from at least one generally recognized prevention strategy. ${ }^{5}$ The challenge, however, lies in encouraging at-risk individuals to adopt evidence-based prevention recommendations. ${ }^{6}$

Naturopathic medicine is a system of medicine that emphasizes patient education, self-care, nutrition, healthy lifestyle, and disease prevention. ${ }^{7-9}$ Many of the CVD prevention strategies studied and found to be effective are also usual recommendations made to patients by naturopathic doctors. ${ }^{10}$ Nevertheless, their effectiveness as part of a system of individualized whole-person care has not

From the Center for Health Outcomes and Pharmacoeconomics Research (Dr Herman), University of Arizona, and the RAND Corporation, Santa Monica, Calif; Department of Research and Clinical Epidemiology (Drs Szczurko, Cooley, and Seely), Canadian College of Naturopathic Medicine, Toronto, Ontario, Canada; and Department of Social and Administrative Pharmacy (Drs Szczurko and Cooley), University of Toronto, Toronto, Ontario, Canada

This project was funded by the Joint Benefits Committee of the Canadian Union of Postal Workers and the Canada Post Corporation. During the study, Dr Cooley was supported by a SickKids Foundation Training Award in Complementary/Alternative Health Care.

The authors declare no conflicts of interest.

This is an open-access article distributed under the terms of the Creative Commons Attribution-NonCommercial-NoDerivatives 3.0 License, where it is permissible to download and share the work provided it is properly cited. The work cannot be changed in any way or used commercially.

Address correspondence to: Patricia M. Herman, ND, PhD, RAND Corporation, 1776 Main Street, PO Box 2138, Santa Monica, CA 90407 (pherman@ rand.org).

Copyright (C) 2014 by American College of Occupational and Environmental Medicine

DOI: 10.1097/JOM.0000000000000066 been evaluated. This study is a cost-effectiveness analysis alongside a pragmatic, multi-worksite-based, randomized controlled trial of the addition of naturopathic care to "enhanced" usual care (usual care plus biometric screening) for primary prevention of CVD.

\section{METHODS}

This section focuses on the methods used for the economic evaluation. More detail on the design of the underlying effectiveness trial and its clinical outcomes can be found in a companion publication ${ }^{11}$ and at http://clinicaltrials.gov/ct2/show/ NCT00718796. In brief, the trial recruited workers aged 25 to 65 years, with a current primary care physician from three Canada Post Corporation worksites (Edmonton, Toronto, and Vancouver). Each interested worker first consented to be screened for CVD risk. Then, 246 of those with the highest risk consented to be randomized to either enhanced usual care (EUC: three 1-hour biometric screening and data collection visits) or naturopathic care plus EUC (NC+EUC; the above plus an individualized mix of lifestyle counseling and nutritional and botanical medicine offered during the data collection visits plus up to four additional 30-minute visits over the year). Both groups received care in an on-site clinic from licensed naturopathic doctors, and were asked to continue to see their family physician as needed for their general health care needs. After consent to the trial and before randomization, participants were asked to provide separate informed consent to have their sick leave and medical claims data extracted from company databases. This economic evaluation is based on the subset of patients who provided this consent and these data. The study was approved by the Research Ethics Board of the Canadian College of Naturopathic Medicine.

\section{MEASURES}

The collection of biometric and self-report data occurred at baseline and 6 and 12 months. The medical claims and sick leave data for each participant were extracted at study end for the period 6 months before baseline through the full study year. The claims data covered prescription medications and visits to chiropractors, physiotherapists, massage therapists, and acupuncturists, and included the total dollar amounts of the claims submitted and paid. Sick leave data were all sick leave hours paid by the employer. Participants reported on visits to their conventional doctors (covered by provincial insurance) and their use of natural health products (NHPs) on a cost questionnaire. Presenteeism (ie, productivity while at work) was captured using the Health and Performance Questionnaire. ${ }^{12}$ Quality-adjusted life years (QALYs) were calculated on the basis of SF-6D scores. ${ }^{13}$

\section{COSTS}

Costs are reported in 2008 Canadian dollars. Unit costs for health care utilization and productivity losses are shown in Table 1. Laboratory costs for the biometric screenings were identical between groups and ignored in this analysis. NHP costs were obtained from on-line sites such as drugstore.com. 
TABLE 1. Unit Costs and Sources

\begin{tabular}{lc}
\hline Resource & $\begin{array}{c}\text { Unit Cost } \\
\text { (2008 Canadian } \\
\text { Dollars) }\end{array}$ \\
\hline $\begin{array}{l}\text { Naturopathic doctor visit (per hour)* } \\
\text { Biometric screening for the control } \\
\text { group (per screening) } \dagger\end{array}$ & $\$ 152.50$ \\
Conventional doctor visit $\ddagger$ & $\$ 21.00$ \\
Chiropractic visit§ & $\$ 42.35$ \\
Physiotherapist visit $\S$ & $\$ 43.31$ \\
Massage visit $§$ & $\$ 65.67$ \\
Acupuncture visit $§$ & $\$ 59.82$ \\
Employer cost (per hour) & $\$ 57.03$ \\
\hline
\end{tabular}

*Average of range of $\$ 125$ to $\$ 180$ per hour from the Canadian Association of Naturopathic Doctors Web site (http://www.cand.ca/index.php?39), accessed on-line September 10, 2010.

$\nmid$ Personal telephone communications on August 30 and September 10, 2010, with representative of Total Wellness, a large company providing biometric screening in the United States and Canada. Estimate of labor (nonlaboratory) costs for each screening.

$\ddagger$ Cost of a repeat consultation (A006) from the Schedule of Benefits for Physician Services, Ontario Health Insurance Program (http://health.gov.on.ca/ english/providers/program/ohip/sob/physserv/a_consul.pdf), accessed on-line September 10, 2010.

\$Average cost per visit assuming each claim represents one visit Post.

\|Average employee cost (salary and $20 \%$ benefits) per hour provided by Canada

\section{ANALYSIS}

Cost-effectiveness is calculated from the societal and employer perspectives. Effectiveness for both perspectives is measured in terms of QALY gains over the 1-year study period and reductions in 10-year CVD event and mortality risk. Quality-adjusted life years are calculated as the area under the SF-6D score curve over the year. Individuals' 10-year CVD event risk was calculated using an algorithm on the basis of sex, age, total cholesterol, high-density lipoprotein cholesterol, systolic blood pressure, hypertension medication use, smoking status, and diabetes diagnosis. ${ }^{14}$ The 10 -year risk of CVD death used a different algorithm with the same variables. ${ }^{15}$ Because of the 1-year timeframe of the study, neither costs nor effects are discounted.

This analysis follows intent-to-treat principles. Missing selfreport and biometric data were handled using multiple imputation methods. ${ }^{16,17}$ Because cost data tend to be highly skewed, biascorrected and accelerated bootstrap estimates are used to determine confidence intervals for costs (1000 replications). ${ }^{18,19}$ The bootstrapped societal cost-CVD risk pairs are also shown on a costeffectiveness plane. $^{20}$

Univariate sensitivity analyses were conducted to examine the effects of missing data imputation, including participants with different baseline CVD risks (low risk versus moderate/high risk), and including actual rather than allowed visits. Baseline betweengroup differences were analyzed using $t$ tests (continuous variables) and chi-squared tests (frequencies). All calculations used Excel 2007 SP2 (Microsoft Corporation, Redmond, WA) or SPSS Statistics 17.0 (SPSS, Inc., Chicago, IL).

\section{RESULTS}

Figure 1 shows the flow of participants through the study. Approximately 400 workers with the highest CVD risk were contacted after screening and 246 consented to the effectiveness trial. This economic evaluation is limited to the 156 of these ( 77 or $63.1 \%$ of those randomized to the EUC group and 79 or $63.7 \%$ of those randomized

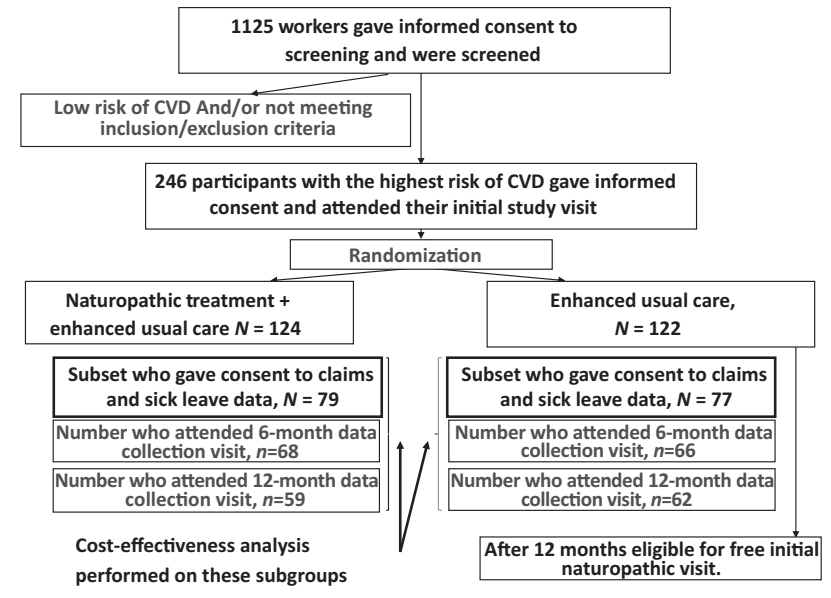

FIGURE 1. Flow of participants through the study.

to the NC+EUC group) who also consented to having their medical claims and sick leave data accessed. When those who did and did not consent to these data were compared, no statistically significant differences were found across baseline characteristics, outcomes, or tendency to miss study visits. Table 2 shows baseline characteristics for the two groups analyzed in this study. Only two comparisons (out of the 44 tested) had $P$ values of less than 0.05 . At baseline, almost twice as many participants in the NC+EUC group were taking hypertensive medications $(P=0.050)$ and had had a visit with their physician in the past month $(P=0.022)$. Nevertheless, given the number of comparisons, these unadjusted $P$ values are not indicative of statistical significance.

Resource use over the study year for each group (net of baseline use) and health-related quality-of-life scores are shown in Table 3. The intervention hours for both groups do not include study protocol time (eg, time used to consent participants, explain the study, and collect self-report study data), do not include the 12-month visit (which did not affect 12-month study outcomes), and include time to collect and explain biometric screening data to participants (20 minutes per screening times two visits). The main differences seen between groups in resource use other than intervention costs were reductions in conventional doctor visits ( 4 fewer visits over the year, $95 \%$ confidence interval: 1.3 to 7.0 ) and in hours lost to presenteeism (55 fewer hours lost, not statistically significant) for the NC+EUC group.

The mean incremental cost of naturopathic care to society is $-\$ 1138$ (ie, a net saving of $\$ 1138$ compared to EUC alone) per participant (Table 4). As can be seen in Tables 3 and 4, a vast majority of the cost savings are attributable to reductions in productivity losses, specifically losses because of reduced productivity while at work (presenteeism). Naturopathic care also results in a net saving of $\$ 1187$ to employers per participant, assuming that the employer pays the full cost of naturopathic care and would have paid for the biometric screenings. These cost savings are associated with significant reductions in CVD disease and mortality risk. Cardiovascular disease event risk over the next 10 years was reduced by 3.3 percentage points (ie, 3.3 fewer workers out of 100 expected to have a CVD event; number needed to treat $=30$ ) and CVD mortality risk by 0.9 percentage points (ie, almost one fewer worker out of 100 dying of CVD in the next 10 years). Figure 2 shows the cost-CVD event risk reduction plane for the societal perspective. Across the 1000 bootstrapped societal cost-CVD risk estimate pairs, all show a reduction in CVD risk and 85\% show cost savings. 
TABLE 2. Baseline Characteristics of Participants Included in Economic Evaluation

\begin{tabular}{|c|c|c|c|}
\hline Characteristic & $\begin{array}{l}\text { Naturopathic } \\
\text { Care }(n=79)\end{array}$ & $\begin{array}{c}\text { Enhanced Usual } \\
\text { Care }(n=77)\end{array}$ & $P$ \\
\hline Female, $\%$ & 36.7 & 29.9 & 0.399 \\
\hline Average age, yr & 49.9 & 48.4 & 0.301 \\
\hline Smokers, \% & 15.2 & 13.0 & 0.819 \\
\hline Systolic blood pressure, $\mathrm{mm} \mathrm{Hg}$ & 125.7 & 123.3 & 0.374 \\
\hline Hypertensive medication, $\%$ & 27.8 & 14.3 & 0.050 \\
\hline Total cholesterol/high-density lipoprotein cholesterol & 5.6 & 5.4 & 0.666 \\
\hline Hyperlipidemia medication, $\%$ & 15.2 & 11.7 & 0.640 \\
\hline Diabetes diagnosis, $\%$ & 11.4 & 6.5 & 0.402 \\
\hline Diabetes medication, $\%$ & 10.1 & 5.2 & 0.369 \\
\hline 10-yr CVD event risk & 0.110 & 0.095 & 0.205 \\
\hline $10-$ yr risk $<10 \%$ & 61.0 & 62.3 & \\
\hline 10 -yr risk $10 \%-20 \%$ & 23.4 & 26.0 & 0.762 \\
\hline $10-\mathrm{yr}$ risk $>20 \%$ & 15.6 & 11.7 & \\
\hline 10-yr CVD mortality risk & 0.021 & 0.015 & 0.150 \\
\hline Health-related quality of life (SF-6D score) & 0.73 & 0.74 & 0.707 \\
\hline Presenteeism* & 8.2 & 7.9 & 0.347 \\
\hline \multicolumn{4}{|l|}{ Past 6 mos } \\
\hline Absentee hours & 34.2 & 34.7 & 0.937 \\
\hline Conventional doctor visits $\dagger$ & $0.74(45)$ & $0.45(35)$ & 0.022 \\
\hline Chiropractic visits $\dagger$ & $0.41(10)$ & $0.86(8)$ & 0.288 \\
\hline Physiotherapy visits $\dagger$ & $1.35(9)$ & $0.69(6)$ & 0.351 \\
\hline Massage visits $\dagger$ & $0.72(14)$ & $0.45(12)$ & 0.381 \\
\hline Acupuncture visits $\dagger$ & $0.40(6)$ & $0.27(6)$ & 0.577 \\
\hline Natural health product use, $\%$ & 51.9 & 38.7 & 0.108 \\
\hline
\end{tabular}

TABLE 3. Average Resource Use (Net of Baseline Use) and Health-Related Quality of Life

\begin{tabular}{|c|c|c|c|}
\hline Resource & $\begin{array}{l}\text { Naturopathic } \\
\text { Care }(n=79)\end{array}$ & $\begin{array}{l}\text { Enhanced Usual } \\
\text { Care }(n=77)\end{array}$ & Difference \\
\hline $\begin{array}{l}\text { Intervention visit hours } \\
\text { (net of } \\
\text { protocol-specific hours) }\end{array}$ & 2.53 & 0.67 & 1.87 \\
\hline \multicolumn{4}{|c|}{ Health care utilization over 12 mos (bootstrap BCa 95\% CI)* } \\
\hline $\begin{array}{l}\text { Conventional doctor } \\
\text { visits }\end{array}$ & $-1.2(-3.1,0.8)$ & $2.9(1.0,5.3)$ & $-4.1(-7.0,-1.3)$ \\
\hline Chiropractor visits & $-0.0(-0.8,0.7)$ & $-0.9(-2.3,0.1)$ & $0.9(-0.4,2.3)$ \\
\hline Physiotherapist visits & $-0.3(-2.5,1.3)$ & $1.4(0.3,3.4)$ & $-1.7(-4.2,0.5)$ \\
\hline Massage visits & $-0.1(-0.8,0.5)$ & $0.2(-0.4,0.9)$ & $-0.3(-1.2,0.7)$ \\
\hline Acupuncture visits & $-0.4(-1.2,0.3)$ & $0.2(-0.3,0.7)$ & $-0.5(-1.5,0.3)$ \\
\hline Lost absenteeism hours & $10.4(-13.1,41.3)$ & $4.3(-26.3,31.6)$ & $6.1(-30.8,47.1)$ \\
\hline $\begin{array}{l}\text { Lost presenteeism } \\
\text { hours }\end{array}$ & $-57.3(-111.3,-4.3)$ & $-2.3(-65.4,52.9)$ & $-55.0(-130.2,28.1)$ \\
\hline \multicolumn{4}{|c|}{ Health-related quality of life (SF-6D, score out of 100$)$ mean $(95 \% \mathrm{CI}) \dagger$} \\
\hline Baseline & $0.73(0.71,0.76)$ & $0.74(0.72,0.76)$ & $-0.01(-0.04,0.02)$ \\
\hline $6 \mathrm{mos}$ & $0.77(0.75,0.79)$ & $0.78(0.76,0.80)$ & $-0.01(-0.04,0.03)$ \\
\hline $12 \mathrm{mos}$ & $0.73(0.71,0.76)$ & $0.72(0.70,0.74)$ & $0.01(-0.02,0.05)$ \\
\hline
\end{tabular}

*Bias-corrected and accelerated bootstrap $95 \%$ confidence interval.

$\dagger$ Standard error-based $95 \%$ confidence interval adjusted for missing data imputation estimate variance.

CI, confidence interval. 
TABLE 4. Costs (Net of Baseline; 2008 Canadian dollars), and Changes in CVD Event and Mortality Risk and Quality-Adjusted Life Years*

\begin{tabular}{lccc}
\hline Resource & $\begin{array}{c}\text { Naturopathic } \\
\text { Care }(\boldsymbol{n}=\mathbf{7 9})\end{array}$ & $\begin{array}{c}\text { Enhanced Usual } \\
\text { Care }(\boldsymbol{n}=\mathbf{7 7})\end{array}$ & Difference \\
\hline Intervention visit costs, $\$$ & 386 & 42 & 344 \\
Conventional doctor visit costs, $\$$ & $-50(-125,56)$ & $124(49,241)$ & $-174(-288,-37)$ \\
Other visit costs, $\$$ & $-46(-206,100)$ & $76(-5,235)$ & $-122(-319,67)$ \\
CVD medication costs, $\$$ & $17(-23,74)$ & $50(10,166)$ & $-32(-97,57)$ \\
Non-CVD medication costs, $\$$ & $131(72,225)$ & $50(-14,141)$ & $81(-9,197)$ \\
Natural health product costs, $\$$ & $277(172,440)$ & $71(11,203)$ & $206(72,380)$ \\
Total direct costs, $\$$ & $715(508,972)$ & $413(226,718)$ & $302(-2,666)$ \\
Lost productivity costs, $\$$ & $-1358(-2411,177)$ & $82(-1545,1966)$ & $-1440(-3282,1432)$ \\
Total societal costs, $\$$ & $-643(-1763,897)$ & $495(-1172,2558)$ & $-1138(-3039,1857)$ \\
Other visit costs paid by the employer, $\$$ & $-54(-159,45)$ & $57(-8,205)$ & $-111(-247,41)$ \\
Medication costs paid by the employer, $\$$ & $63(13,136)$ & $41(-15,133)$ & $21(-62,127)$ \\
Total employer costs $\dagger, \$$ & $-964(-2041,566)$ & $222(-1436,2183)$ & $-1187(-3081,1693)$ \\
CVD event risk $\neq, \%$ & $-2.5(-3.7,-1.2)$ & $0.8(-0.1,1.7)$ & $-3.3(-4.8,-1.7)$ \\
CVD mortality risk $\neq, \%$ & $-0.5(-1.0,0.1)$ & $0.4(0.0,0.8)$ & $-0.9(-1.6,-0.2)$ \\
Quality-adjusted life years & $0.02(0.00,0.03)$ & $0.01(-0.00,0.03)$ & $0.01(-0.02,0.03)$ \\
\hline
\end{tabular}

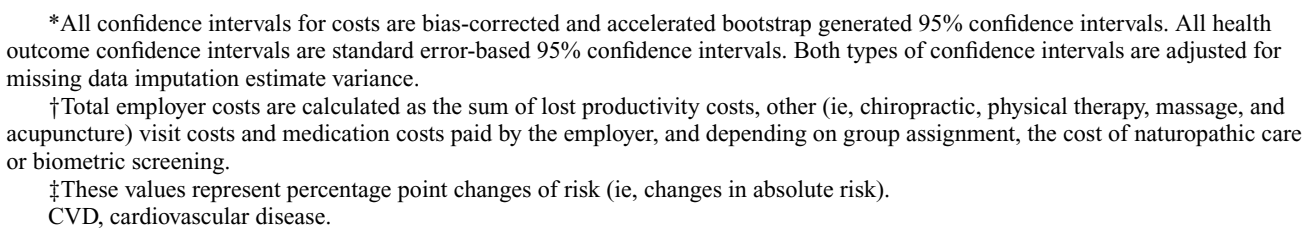

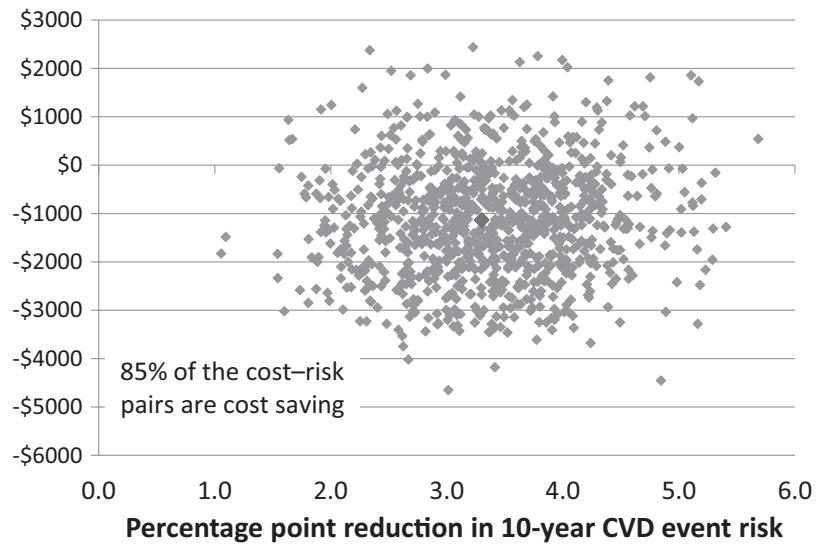

FIGURE 2. Cost-effectiveness plane for societal perspective.

\section{Sensitivity Analyses}

The similarity of the first two columns in the sensitivity analysis results (Table 5) indicates the success of the missing data imputation methods used. The last two columns show the results of the analyses by baseline CVD event risk. Overall, both average incremental costs and risk reductions are higher for the moderate/high-risk participants. Incremental direct costs for moderate/high-risk participants are lower than for low-risk participants (mainly because of reductions in conventional doctor visits), but the difference in lost productivity costs more than offsets this. The difference in productivity costs mainly occurs in the control group. The average reduction in productivity losses in the treatment group is similar no matter what the baseline risk level (an average reduction of \$1296 per participant for low-risk participants and \$1417 for moderate-to-high risk). Nev- ertheless, low-risk participants in the control group had an average increase of $\$ 1165$ per participant in lost productivity and moderateto-high risk participants had an average reduction of $\$ 1612$.

The CVD event risk reductions for moderate-to-high risk participants are substantially higher (number needed to treat $=18$ ) than for low-risk participants (number needed to treat $=60$ ) and the base case. Nevertheless, there is no real difference in QALYs across risk groups.

Because participants generally attended all their visits, using actual visits rather than the total number allowed (which was done here) did not appreciably change base case results. On average both the $\mathrm{NC}+\mathrm{EUC}$ and the EUC groups attended 1.86 of their two allowed data collection visits, and the $\mathrm{NC}+\mathrm{EUC}$ group attended on average 3.30 of their allowed four additional visits.

\section{CONCLUSIONS}

The addition of naturopathic care to usual care plus biometric screening for this postal worker population results in reductions in CVD risk and in total societal and employer costs. On average this population, whose baseline risk of a CVD event in the next 10 years was just more than $10 \%$, reduced their risk by one third. In addition, the risk of CVD death was reduced by half (average baseline risk was $1.8 \%$ ). The average reduction in risk was even higher for participants who started the study with a moderate-to-high $(\geq 10 \%)$ CVD event risk. These risk reductions were achieved at a small increase in direct costs, but with substantial decreases in indirect/productivity costs.

These risk reductions are comparable to that of pharmacological interventions. A recent review of primary prevention interventions for CVD reported 10-year healthy years of life-saved per 100 participants (HYLS/100) estimates for aspirin of 9.2 in 50-year-olds with moderate risk of a CVD event and 18.1 for those with high risk. ${ }^{21}$ For statin therapy these estimates were 10.6 and 20.2. On the basis of the reductions in CVD risk seen in this study, the addition of naturopathic care to EUC resulted in an average of $18.2 \mathrm{HYLS} / 100$ across 
TABLE 5. Sensitivity Analyses*

\begin{tabular}{|c|c|c|c|c|}
\hline & \multirow[b]{2}{*}{ Base Case } & \multirow{2}{*}{$\begin{array}{l}\text { Including Only Those } \\
\text { With At Least } 2 \text { Data } \\
\text { Collection Visits }\end{array}$} & \multicolumn{2}{|c|}{$\begin{array}{c}\text { Including Only Those With CVD } \\
\text { Event Risk }\end{array}$} \\
\hline & & & $\begin{array}{c}\text { Low } \\
(<10 \% \text { Risk })\end{array}$ & $\begin{array}{l}\text { Moderate/High } \\
(\geq 10 \% \text { Risk })\end{array}$ \\
\hline $\begin{array}{l}\text { Number in NC+EUC and EUC } \\
\text { groups }\end{array}$ & $N=79,77$ & $N=72,68$ & $N=47,48$ & $N=32,29$ \\
\hline Total direct costs, $\$$ & $302(-2,666)$ & $299(16,642)$ & $412(83,845)$ & $154(-412,830)$ \\
\hline Lost productivity costs, $\$$ & $-1440(-3282,1432)$ & $-1500(-3516,826)$ & $-2582(-4868,-163)$ & $316(-3582,5181)$ \\
\hline Total societal costs, $\$$ & $-1138(-3039,1857)$ & $-1201(-3276,1184)$ & $-2169(-4429,395)$ & $470(-3482,5613)$ \\
\hline Total employer costs, $\$$ & $-1187(-3081,1693)$ & $-1226(-3229,1189)$ & $-2296(-4569,185)$ & $511(-3591,5468)$ \\
\hline CVD event risk $\dagger, \%$ & $-3.3(-4.8,-1.7)$ & $-3.3(-4.8,-1.7)$ & $-1.7(-3.1,-0.3)$ & $-5.6(-8.8,-2.4)$ \\
\hline CVD mortality risk $\dagger, \%$ & $-0.9(-1.6,-0.2)$ & $-1.1(-1.7,-0.4)$ & $-0.2(-0.7,0.3)$ & $-1.9(-3.5,-0.3)$ \\
\hline Quality-adjusted life years & $0.01(-0.02,0.03)$ & $0.01(-0.02,0.03)$ & $0.00(-0.03,0.03)$ & $0.01(-0.02,0.04)$ \\
\hline
\end{tabular}

*All confidence intervals for costs are bias-corrected and accelerated bootstrap generated $95 \%$ confidence intervals. All health outcome confidence intervals are standard error-based $95 \%$ confidence intervals. Both types of confidence intervals are adjusted for missing data imputation estimate variance. All cost and health outcome estimates are incremental (ie, NC+EUC values minus EUC values). All costs are 2008 Canadian dollars.

$\dagger$ These values represent percentage point changes of risk (ie, changes in absolute risk)

CVD, cardiovascular disease; EUC, enhanced usual care; NC, naturopathic care.

all participants and $30.3 \mathrm{HYLS} / 100$ for participants with moderate to high risk.

Naturopathic care also provided substantially larger impacts than other nonpharmacological primary prevention interventions. For example, an intervention consisting of biometric screening plus up to 60 minutes per year of telehealth lifestyle counseling for participants with moderate-to-high CVD risk resulted in a risk reduction of 1.8 percentage points compared with usual care alone. ${ }^{22}$ Another study targeted participants with baseline 10-year CVD event risks similar to this study, provided biometric screening to both groups, and used a fairly intensive intervention (1 year of counseling sessions plus group activities focused on physical activity and nutrition). ${ }^{23}$ It resulted in a 0.3 percentage point reduction in 10 -year coronary heart disease risk in low-income women. We found no significant changes in QALYs during the study year. Nevertheless, none were expected given the focus on reducing future health risks. A 3-year study of diet and exercise for the reduction of CVD risk in moderate-to-high-risk individuals also found no significant change in QALYs during the first year, but a significant gain by year 3. ${ }^{24}$

The naturopathic intervention was more expensive in terms of direct medical costs (\$302 per participant more; Table 4) than biometric screening alone. Nevertheless, this cost compares favorably to the annual wholesale cost of statin drugs alone which, according to one source, ranges from $\$ 347$ to $\$ 818$ in 2006 Canadian dollars. ${ }^{25}$ The impact of naturopathic care on indirect (productivity loss) costs was more dramatic, especially in terms of presenteeism. Other studies have shown that various illnesses can have a larger impact on presenteeism than absenteeism. ${ }^{26}$ Nevertheless, with the focus on reducing future disease risk, the size of the impacts is surprising, but not unprecedented. See, for example, a worksite health promotion study that found similar-sized presenteeism gains ( $\$ 1364$ over a year). ${ }^{27}$

On average presenteeism improved across the year (lost productivity costs decreased) in the NC+EUC group and worsened in the EUC group. Nevertheless, sensitivity analyses show that those in the EUC group with moderate-to-high baseline CVD risk had a substantial improvement in presenteeism, whereas those with low risk worsened substantially. It is unclear why presenteeism was so different for EUC group members with different baseline CVD risks. As discussed previously, changes in health-related quality-of-life were minimal during the study year. One possible explanation is that because all participants were encouraged to share their biometric screening results with their conventional doctors, those in the EUC group with moderate-to-high baseline CVD risk may have received more physician attention than those with low risk. The moderate-to-high-risk group did have about four times the number of conventional doctor visits than those with low baseline risk. Those with moderate-to-high risk may also have been more motivated to make improvements in their health, which could improve presenteeism.

This study has both limitations and strengths. The CVD event and mortality risk estimates were based on equations developed from the Framingham Heart Study. ${ }^{14,15}$ The accuracy of these equations has been tested in different populations and found to be fairly high. ${ }^{28}$ Nevertheless, validation in Canadian populations is limited. ${ }^{29} \mathrm{Al}-$ though claims data were available for prescription medications and visits to other practitioners, the use of NHPs and conventional doctor visits relied on self-report. Similarly, company records of sick leave were available for absenteeism, but presenteeism was self-report. Finally, some of the NHPs used in this study were provided to participants at a discount, and those prices paid were used in the cost analysis. Nevertheless, because retail costs for NHPs vary widely depending on brand and outlet, these discounted prices were still representative of the full retail price paid for similar products elsewhere. Strengths of the study include the availability of electronic medical claims and sick leave data for the majority of the effectiveness study participants, and the similarity between participants who did and did not consent to these data. Retention of participants was high $(91 \%$ and $88 \%$ of the NC+EUC and EUC groups, respectively, attended two of three data collection visits), missing data were rigorously addressed, and the intervention was individualized, evidence-based, and could be applied by a wide variety of practitioner types.

In conclusion, this pragmatic, multi-worksite randomized trial demonstrates that a naturopathic approach to the primary prevention of CVD has the potential to significantly reduce CVD risk for those with a wide range of baseline risk. These risk reductions come at a small increase in medical costs, but with the potential for substantial improvements in worker productivity. Further research into similar nonpharmacological, whole-person approaches to CVD prevention is justified. 


\section{ACKNOWLEDGMENTS}

The authors acknowledge contributions from Gillian Flower, Heidi Fritz, Chris Habib, and Shawn Manske in data compilation. The authors also thank Seroyal International for providing discounted NHPs to trial participants.

\section{REFERENCES}

1. Centers for Disease Control and Prevention. Leading causes of death. FastStats. Washington, DC: Centers for Disease Control and Prevention; 2007.

2. Statistics Canada. Leading Causes of Death. Statistics Canada; 2006.

3. Public Health Agency of Canada. Tracking heart disease and stroke in Canada. In: Public Health Agency of Canada, Canadian Institute for Health Information, Canadian Stroke Network, Heart and Stroke Foundation of Canada, Statistics Canada, eds. Ottawa, Ontario: Public Health Agency of Canada; 2009:132.

4. American Heart Association. Heart Disease \& Stroke Statistics-2010 Update. Dallas, TX: American Heart Association; 2010.

5. Kahn R, Robertson RM, Smith R, Eddy D. The impact of prevention on reducing the burden of cardiovascular disease. Diabetes Care. 2008;31:16861696.

6. Libby P. The forgotten majority: unfinished business in cardiovascular risk reduction. J Am Coll Cardiol. 2005;46:1225-1228.

7. Murray MT, Pizzorno JE. Naturopathic Medicine. In: Jonas WG, Levin JS, eds. Essentials of Complementary and Alternative Medicine. Philadelphia, PA: Lippincott Williams and Wilkins; 1999:304-321.

8. Fleming SA, Gutknecht NC. Naturopathy and the primary care practice. Prim Care Clin Office Pract. 2010;37:119-136.

9. Smith MJ, Logan AC. Naturopathy. Med Clin North Am. 2002;86: 173-184.

10. Boon HS, Cherkin DC, Erro J, et al. Practice patterns of naturopathic physicians: results from a random survey of licensed practitioners in two US States. BMC Complement Altern Med. 2004;4:14.

11. Seely D, Szczurko O, Cooley K, et al. Naturopathic medicine for the prevention of cardiovascular disease: a randomized clinical trial. Can Med Assoc J. 2013;185:E409-E416.

12. Kessler RC, Catherine Barber MPA, Beck A, et al. The World Health Organization Health and Work Performance Questionnaire (HPQ). J Occup Environ Med. 2003;45:156.

13. Brazier J, Roberts J, Deverill M. The estimation of a preference-based measure of health from the SF-36. J Health Econ. 2002;21:271-292.

14. D'Agostino RB, Vasan RS, Pencina MJ, et al. General cardiovascular risk profile for use in primary care: the Framingham Heart Study. Circulation. 2008;117:743-753.
15. Anderson KM, Odel PM, Wilson PWF, Kannel WB. Cardiovascular disease risk profiles. Am Heart J. 1991;121:293-298.

16. Briggs A, Clark T, Wolstenholme J, Clarke P. Missing ... presumed at random: cost-analysis of incomplete data. Health Econ. 2003;12:377-392.

17. McKnight PE, McKnight KM, Sidani S, Figueredo AJ. Missing Data: A Gentle Introduction. New York, NY: The Guilford Press; 2007.

18. Barber JA, Thompson SG. Analysis of cost data in randomized trials: an application of the non-parametric bootstrap. Stat Med. 2000;19: 3219-3236.

19. Efron B, Tibshirani RJ. An Introduction to the Bootstrap. Boca Raton, FL: Chapman \& Hall/CRC; 1994.

20. Drummond MF, Sculpher MJ, Torrance GW, O'Brien B, Stoddart GL. Methods for the Economic Evaluation of Health Care Programmes. Oxford: Oxford University Press; 2005.

21. Franco $\mathrm{OH}$, der Kinderen AJ, De Laet C, Peeters A, Bonneux L. Primary prevention of cardiovascular disease: cost-effectiveness comparison. Int $J$ Technol Assess Health Care. 2007;23:71-79.

22. Wister A, Loewen N, Kennedy-Symonds H, McGowan B, McCoy B, Singer J. One-year follow-up of a therapeutic lifestyle intervention targeting cardiovascular disease risk. Can Med Assoc J. 2007;177: 859-865.

23. Finkelstein EA, Troped PJ, Will JC, Palombo R. Cost-effectiveness of a cardiovascular disease risk reduction program aimed at financially vulnerable women: the Massachusetts WISEWOMAN project. J Womens Health Gender Based Med. 2002;11:519-526.

24. Eriksson MK, Hagberg L, Lindholm L, Malmgren-Olsson E-B, Osterlind J, Eliasson M. Quality of life and cost-effectiveness of a 3-year trial of lifestyle intervention in primary health care. Arch Intern Med. 2010;170: $1470-1479$.

25. Tran YBL, Frial T, Miller PSJ. Statin's cost-effectiveness: a Canadian analysis of commonly prescribed generic and brand name statins. Can J Clin Pharmacol. 2008;14:e205-e214.

26. Goetzel RZ, Long SR, Ozminkowski RJ, Hawkins K, Wang S, Lynch W. Health, absence, disability, and presenteeism cost estimates of certain physical and mental health conditions affecting U.S. employers. J Occup Environ Med. 2003;46:398-412.

27. Mills PR, Kessler RC, Cooper J, Sullivan S. Impact of a health promotion program on employee health risks and work productivity. Am J Public Health. 2007;22:45-53.

28. Brindle P, Beswick A, Fahey T, Ebrahim S. Accuracy and impact of risk assessment in the primary prevention of cardiovascular disease: a systematic review. Heart. 2006;92:1752-1759.

29. Grover SA, Hemmelgarn B, Joseph L, Milot A, Tremblay G. The role of global risk assessment in hypertension therapy. Can J Cardiol. 2006;22: 606-613. 